\title{
A randomized controlled trial of a mindfulness-based intervention in social workers working during the COVID-19 crisis
}

\author{
Navid R. Hosseinzadeh Asl ${ }^{1}$ \\ Accepted: 22 July 2021 / Published online: 9 August 2021 \\ (C) The Author(s), under exclusive licence to Springer Science+Business Media, LLC, part of Springer Nature 2021
}

\begin{abstract}
As one of the frontline professionals during the coronavirus (COVID-19) pandemic, social workers can face tremendous pressure, which can lead to mental health problems. The objective of this study was to investigate whether a brief mindfulness-based intervention had short- and middle-term effects on social workers working during the COVID-19 pandemic. In a randomized controlled trial, 49 social workers were assigned to an experimental group $(n=28)$ or a waitlist control group $(n=21)$. The intervention was a four-week mindfulness-based program. The outcome variables were measured at pre- and posttest, and at one-month follow-up test. At post-test and follow-up, the workers in the experimental group reported higher mean scores in psychological flexibility and self-compassion and lower mean scores in depression compared to the workers in the waitlist control group. Although the experimental group also showed lower mean scores than the waitlist control group in anxiety and stress at both post-test and follow, the differences were not statistically significant. The findings suggest that a brief mindfulness-based intervention can improve psychological flexibility, self-compassion, and depression in social workers working during the COVID-19 crisis, leading to protected mental health, adding support to continuing development of such efficient mindfulness-based programs. Future studies should use larger samples and examine brief interventions' working mechanisms.
\end{abstract}

Keywords COVID-19 $\cdot$ Psychological health $\cdot$ Brief mindfulness-based intervention · Online intervention $\cdot$ Social workers

\section{Introduction}

The world is currently struggling with the coronavirus disease 2019 (COVID-19) pandemic, which has been having a devastating impact on all aspects of everyday life (Haleem et al. 2020; Chakraborty and Maity 2020), and it appears that the effects will last for quite a while. In addition to the potentially dangerous physical health repercussions of contracting COVID-19, it causes an enormous amount of psychological stress on individuals, particularly under lockdown and social distancing mandates, resulting in decreased psychological well-being and increased depression and anxiety contrasted to the pre-COVID-19 period (Vindegaard and Benros 2020).

Working in the frontline during the COVID-19 crisis imposes even more pressure on individuals such as general practitioners and primary care workers, making them highly prone to mental health problems (Amerio et al. 2020; Jatta et al.

Navid R. Hosseinzadeh Asl

nhosseinzadehasl@aydin.edu.tr

1 Department of Social Work, Istanbul Aydin University, Istanbul, Turkey
2021). As part of frontline workers, social workers have also been tackling the difficulties of individuals and communities, especially the vulnerable population, who are the most seriously affected by the adverse consequences of the COVID-19 pandemic (Brown 2020). For instance, people have lost their livelihood and needed financial support, many have not had access to social security if they catch COVID-19, and the need for psychological support to cope with stressors such as the loss of relatives or the pandemic itself has rocketed up (Chriscaden 2020). Therefore, there is an unprecedented burden on social workers, who were already facing higher levels of work stress, even before the COVID-19 pandemic, that could lead to both physical and mental health issues (Coyle et al. 2005; Kagan and Itzick 2019; Stanley et al. 2006; Storey and Billingham 2001; Grise-Owens 2016). According to the National Association of Social Workers (NASW 2020a), "social workers, like many health and behavioral health professionals, are concerned about the impact of COVID-19 on their well-being, the people to whom they provide services, their families, and others in the community." NASW highlights the point that, against the challenges of the job, social workers need to apply proper self-care methods to reduce the adverse effects on their health (NASW 2020b). 
Research has supported that applying self-care practices by social workers will bring benefits for the worker, client, organizations, and consequently for the profession (Cuartero and Campos-Vidal 2019; Willis and Molina 2018; Acker 2018; Lewis and King 2019). For instance, Cuartero and CamposVidal (2019) have found that social workers who applied selfcare practices reported lower levels of compassion fatigue as well as higher levels of satisfaction. Therefore, especially in the COVID-19 crises, social workers need to acquire an efficient self-care practice.

Mindfulness has recently been one of the well-known evidence-based practices and proposed by studies (e.g. McGarrigle and Walsh 2011; Hick 2008; Gockel and Deng 2016; McCusker 2021) to promote self-care effectively among social workers. In a systematic review of self-care intervention studies in social workers, Griffiths et al. (2019) have concluded that mindfulness practices help social workers maintain their well-being and are essential for modelling and ensuring successful client service delivery.

Mindfulness has been described as "the awareness that emerges through paying attention on purpose, in the present moment, and non-judgmentally to the unfolding of experience moment by moment" (Kabat-Zinn 2003). Mindfulness-based interventions such as mindfulness-based stress reduction (MBSR; Kabat-Zinn 2003) and mindfulness-based cognitive therapy (MBCT; Segal et al. 2013) aim to develop mindfulness in their participants through an eight-week schedule containing a variety of practices such as sitting meditation, body scan, and walking meditation. Research has shown that mindfulness-based interventions can effectively decrease participants' psychological distress (the parameters such as depression, anxiety, and stress) and improve their selfcompassion and psychological flexibility, which both are positively and strongly related to mental health (e.g. Vonderlin et al. 2020; Dawson et al. 2020; Zhou et al. 2020; Marshall and Brockman 2016; Inwood and Ferrari 2018).

Self-compassion and psychological flexibility are relatively new concepts in social work literature, and both have been shown to correlate positively with better mental health (Marshall and Brockman 2016). Self-compassion has been defined as showing compassion to oneself when suffering or experiencing personal failure (Neff 2003b). It is a skilled response that helps the individual to deal with unchangeable hardship (Hughes et al. 2021). Psychological flexibility has been defined as an individual's ability to embrace and contact the present moment, tolerate difficult thoughts and emotions without unnecessary defense or avoidance, and act following chosen values (Hayes et al. 2006). The research supported that mindfulness practices can cultivate self-compassion and psychological flexibility (Marais et al. 2020; Wasson et al. 2020). Therefore, improving the levels of these two skills can mitigate the hardships that social workers are facing during the COVID-19 pandemic, resulting in better mental health.
The number of interventional studies that investigated the impact of mindfulness practices on individuals' mental health during the COVID-19 pandemic is limited; nevertheless, they have reported promising results. Almost all the reviewed studies were congruently reported that, after participating in mindfulness interventions, the participants' mental health and wellbeing improved (Lim et al. 2021; Zhang et al. 2021; Weis et al. 2021; Matiz et al. 2020; Farris et al. 2021).

Despite the benefits those standard mindfulness programs (such as MBSR and MBCT) can bring, many have argued the length of such programs (eight weekly two-hour sessions plus 20 to 45 min of homework) that needs a high-level commitment can be tiresome for non-clinical participants, resulting in refusal of participation (Demarzo et al. 2017; Craigie et al. 2016). Therefore, so that the non-clinical population can benefit from mindfulness practices, researchers have proposed briefer versions of mindfulness-based interventions. The effectiveness of these interventions has been backed by evidence that they can improve numerous health-related outcomes, even after a single session and with interventions as brief as five minutes (Howarth et al. 2019). Thus, such brief mindfulness interventions may promote the mental health of social workers who are working during crises such as the Covid-19 pandemic.

Due to strict social distancing measures during the Covid19 pandemic, online mental health interventions as an efficient means of delivering the interventions (Zamorano et al. 2017) have been popular among researchers. A significant body of research has shown that online mindfulness-based approaches are also successful for enhancing mental health outcomes (Spijkerman et al. 2016), making them potentially beneficial and feasible interventions during the Covid-19 pandemic. However, there is a lack of research in investigating the effects of short mindfulness interventions on social workers' mental health. In particular, to our knowledge, there is no study to examine the effectiveness of a brief online mindfulness training program among social workers amid the Covid19 pandemic. Such studies are necessary in order to provide evidence for the efficiency of brief, online, and relatively cheap interventions for social workers working in crisis situations. These interventions can be efficient ways to improve workers' mental health, not only in global pandemics but also in other disasters such as earthquakes, wars, or storms.

Therefore, the aim of the current study was to design a brief online mindfulness-based intervention program and to investigate its effectiveness in improving social workers' mental health during the Covid-19 crisis. In this current study, we tested the following hypotheses: (1) Participants in the intervention group will report a lower level of depression, anxiety, stress, higher level of self-compassion, and psychological flexibility than participants in the control group at post-tests. (2) Participants in the intervention group will report a lower level of depression, anxiety, stress, higher level of self- 
compassion, and psychological flexibility than participants in the control group at follow-up tests.

\section{Methods}

\section{Participants}

The study's participants were social workers working at social services centers located in Ankara-Turkey. Participants were recruited using the convenience sampling method. Initial contacts were made via Instagram (a social networking service) by advertising the intervention program (the purpose, procedures, and inclusion/exclusion criteria). Those interested in the research contacted the first author through Instagram. The eligible individuals were asked to complete a battery of online questionnaires as the study's pre-test. Then, the author randomly allocated the participants to two WhatsApp (a messaging app) groups, one as the experimental group and the other as the control group.

\section{Inclusion and Exclusion Criteria}

An eligible participant needed to be a social worker working full-time at a social services center and possess a device such as a laptop or a smartphone. Unwillingness to provide consent or missing more than one session of the intervention were the exclusion criteria.

Following the exclusion of three participants who did not meet the criteria, 59 individuals were recruited who gave their informed consent and agreed to participate in all aspects of the study. However, two participants from the experimental group did not continue participating in the program, and eight participants from the control group did not fill the post- and follow-up tests; consequently, they dropped out. Twentyeight participants in the experimental group and 21 in the control group completed the entire research process as the study's final sample $(N=49)$.

Participants ranged in age from 25 to 53 , with a mean age of $33.06(\mathrm{SD}=6.02)$, and above half $(n=27,55.1 \%)$ were female. In the baseline measures (pre-tests), there was no statistical difference between the experimental and control groups, supporting the validity of randomization.

\section{Procedures}

Data were collected by administrating a battery of online questionnaires shortly before (pre-test, T1) and after the intervention (post-test, T2), as well as one month after the post-test (follow-up test, T3). The questionnaires were completely anonymous at any test level. Between T1 and T2, the experimental group received the intervention, while the other group acted as waitlist control.

\section{Program Description}

The intervention consisted of four weekly 70-min mindfulness training sessions plus 10 to 20 min of daily meditation as homework. The training program was derived from the principles of MBCT (Segal et al. 2013). It was created and administered by a $\mathrm{PhD}$-level clinical social worker who is a specialist in mindfulness-based interventions with nearly eight years of experience in mindfulness activities. Each session divided into two parts lasting approximately $35 \mathrm{~min}$, with $10 \mathrm{~min}$ of rest time between. The sessions typically began with mindfulness-based psychoeducational materials (e.g. what is acceptance and being non-judgmental) and followed by meditation exercises (e.g. sitting meditation). Pictures and videos were used widely in educational materials to help participants learn more effectively. The outline of the intervention can be found in the supplementary files. Zoom, an app that allows for online meetings and screen sharing, was used to deliver the lessons.

After creating the waitlist control group, they were informed to wait for two months to start the mindfulness training. However, during this period, if they need an emergency relating to their mental health, they were encouraged to contact the authors. After the follow-up tests were administered, the waitlist control group participated in the online mindfulness training. Participants in the waitlist control group were subjected to the same data collection protocol as those in the experimental group.

\section{Measures}

The Depression Anxiety Stress Scales-21 (DASS-21; Lovibond and Lovibond 1995) was used to assess the occurrence of symptoms related to depression, anxiety, and stress over the previous two weeks. The items were rated from 1 (not at all) to 4 (always) points, and each score of a dimension (depression, anxiety, and stress) was the average calculated by its related items. A higher score in a dimension means higher symptoms of that dimension. The Turkish version of the scale has demonstrated to be valid and reliable (Sariçam 2018). In the current study, the alpha coefficients for the three dimensions ranged from .84 to .91 .

The Self-Compassion Scale (SCS; Neff 2003a) was used to measure self-compassion. The SCS is a 26 -item scale that assesses the degree to which respondents have a compassionate orientation to themselves when facing a tough or challenging situation. A five-point Likert scale ranging from 1 (almost never) to 5 (almost always) is used to rate each item. It has six subscales, as well as an overall score of self-compassion. According to Neff (2016), researchers may use scores from sub-scales or the overall scale, depending on their interests. Only the overall score was used in the current study. The scale's higher scores suggest better self-compassion (higher compassionate orientation to themselves). The studies that 
investigated psychometric properties of the Turkish version of the SCS have reported that the scale is reliable and valid (Deniz et al. 2008). In the current study, the alpha coefficients for the overall scale ranged from .85 to .92 .

Acceptance and Action Questionnaire-II (AAQ-II; Bond et al. 2011) was used to assesses psychological inflexibility (the opposite of psychological flexibility), which is defined as experiential avoidance while facing unwanted or distressing psychological events (Hayes et al. 2006). The AAQ-II is a 7point Likert scale with seven items rated from 1 (never) to 7 (always) points. Higher scores indicate greater psychological inflexibility; accordingly, lower scores mean higher psychological flexibility. The Turkish version of the AAQ-II has been found to be a valid and reliable measure (Yavuz et al. 2016). In the current study, the alpha coefficients for the scale ranged from .88 to .93 .

\section{Data Analyses}

Data analysis was conducted using SPSS (version 25.0). The preliminary analysis of pretests revealed no significant difference between the experimental group and waitlist control group in all dependent variables $(p>.05)$. A series of oneway ANCOVAs (Analysis of Covariance) were run to investigate the impact of the brief mindfulness intervention on mental health parameters (depression, anxiety, stress, selfcompassion, and psychological flexibility) by comparing the experimental group and the waitlist control group in posttests, with controlling for the pretests (i.e. covariates). Another series of one-way ANCOVAs were used to investigate the onemonth effects of the intervention by comparing the groups in follow-up tests with considering the pretests as covariates. Regarding each ANCOVA, the assumptions were evaluated: (a) the normality of the data for groups in each comparison, (b) outliers, (c) linear relationships between the independent variables and the covariates, (d) homogeneity of regression slopes, and (e) homogeneity of variances. The assumptions for all the ANCOVAs were satisfied.

\section{Results}

\section{Effects of the Mindfulness Intervention}

The intervention effect was analyzed using ANCOVAs for making between-group comparisons in post-tests, and the results and related statistics are presented in Table 1 . The results revealed that participants in the experimental group reported statistically significant improved outcomes in psychological flexibility $\left[F(1,46)=10.24, p<.01, \eta^{2}=.182\right]$, selfcompassion $\left[F(1,46)=12.24, p<.01, \eta^{2}=.210\right]$, and depression $\left[F(1,46)=7.63, p<.01, \eta^{2}=.142\right]$. As can be seen in Table 1, compared to the waitlist control group, the experimental group reported lower anxiety and stress levels in posttests; however, the differences were not statistically significant $(p>.05)$. Therefore, the brief online mindfulness intervention could improve psychological flexibility, self-compassion, and depression, but not anxiety and stress among social workers.

Similarly to post-tests results, the results of follow-up tests also indicated that the experimental group reported better and statistically significant outcomes in psychological flexibility $\left[\mathrm{F}(1,46)=5.89, p<.05, \eta^{2}=.114\right]$, self-compassion $[\mathrm{F}(1$, $\left.46)=10.71, p<.01, \eta^{2}=.189\right]$, and depression $[\mathrm{F}(1,46)=$ 5.67, $\left.p<.05, \eta^{2}=.110\right]$. Moreover, although the experimental group had lower mean scores in anxiety and stress, the differences were not statistically significant $(p>.05$; see Table 1$)$. Thus, follow-up analyses indicated that the benefits of the brief online mindfulness intervention for social workers could

Table 1 Summary of ANCOVAs and Related Statistics Comparing the Groups in Post- and Follow-up Tests

\begin{tabular}{|c|c|c|c|c|c|c|c|c|c|c|c|c|c|c|c|c|}
\hline & \multicolumn{5}{|c|}{ Experimental group } & \multicolumn{5}{|c|}{ Waitlist control group } & \multirow{2}{*}{\multicolumn{3}{|c|}{$\begin{array}{l}\text { Comparison in post- } \\
\text { tests }\end{array}$}} & \multirow{2}{*}{\multicolumn{3}{|c|}{$\begin{array}{l}\text { Comparison in follow- } \\
\text { ups }\end{array}$}} \\
\hline & \multirow{2}{*}{$\begin{array}{l}\text { Pre-test } \\
M \\
(S D)\end{array}$} & \multicolumn{2}{|c|}{ Post-test } & \multicolumn{2}{|c|}{ Follow-up } & \multirow{2}{*}{$\begin{array}{l}\text { Pre-test } \\
M \\
(S D)\end{array}$} & \multicolumn{2}{|c|}{ Post-test } & \multicolumn{2}{|c|}{ Follow-up } & & & & & & \\
\hline & & $\begin{array}{l}M \\
(S D)\end{array}$ & $\begin{array}{l}A M \\
(S E)\end{array}$ & $\begin{array}{l}M \\
(S D)\end{array}$ & $\begin{array}{l}A M \\
(S E)\end{array}$ & & $\begin{array}{l}M \\
(S D)\end{array}$ & $\begin{array}{l}A M \\
(S E)\end{array}$ & $\begin{array}{l}M \\
(S D)\end{array}$ & $\begin{array}{l}A M \\
(S E)\end{array}$ & $F$ & $p$ & $\eta^{2}$ & $F$ & $p$ & $\eta^{2}$ \\
\hline Inflexibility & $\begin{array}{l}22.11 \\
(5.67)\end{array}$ & $\begin{array}{l}17.89 \\
(4.65)\end{array}$ & $\begin{array}{l}17.39 \\
(0.52)\end{array}$ & $\begin{array}{l}17.96 \\
(4.76)\end{array}$ & $\begin{array}{l}17.56 \\
(0.58)\end{array}$ & $\begin{array}{l}20.38 \\
(4.53)\end{array}$ & $\begin{array}{l}19.29 \\
(4.27)\end{array}$ & $\begin{array}{l}19.96 \\
(0.61)\end{array}$ & $\begin{array}{l}19.19 \\
(3.22)\end{array}$ & $\begin{array}{l}19.73 \\
(0.67)\end{array}$ & 10.24 & .002 & .182 & 5.89 & .019 & .114 \\
\hline Self-compassion & $\begin{array}{l}3.29 \\
(0.54)\end{array}$ & $\begin{array}{l}3.46 \\
(0.52)\end{array}$ & $\begin{array}{l}3.42 \\
(0.03)\end{array}$ & $\begin{array}{l}3.47 \\
(0.52)\end{array}$ & $\begin{array}{l}3.42 \\
(0.04)\end{array}$ & $\begin{array}{l}3.17 \\
(0.55)\end{array}$ & $\begin{array}{l}3.19 \\
(0.53)\end{array}$ & $\begin{array}{l}3.26 \\
(0.4)\end{array}$ & $\begin{array}{l}3.18 \\
(0.52)\end{array}$ & $\begin{array}{l}3.25 \\
(0.04)\end{array}$ & 12.24 & .001 & .210 & 10.71 & .002 & .189 \\
\hline Depression & $\begin{array}{l}12.57 \\
(7.89)\end{array}$ & $\begin{array}{l}9.50 \\
(8.03)\end{array}$ & $\begin{array}{l}9.20 \\
(0.78)\end{array}$ & $\begin{array}{l}11.21 \\
(8.01)\end{array}$ & $\begin{array}{l}10.93 \\
(0.71)\end{array}$ & $\begin{array}{l}11.81 \\
(8.41)\end{array}$ & $\begin{array}{l}12.10 \\
(8.89)\end{array}$ & $\begin{array}{l}12.49 \\
(0.90)\end{array}$ & $\begin{array}{l}13.14 \\
(8.04)\end{array}$ & $\begin{array}{l}13.53 \\
(0.82)\end{array}$ & 7.63 & .008 & .142 & 5.67 & .021 & .110 \\
\hline Anxiety & $\begin{array}{l}6.64 \\
(4.36)\end{array}$ & $\begin{array}{l}4.79 \\
(4.05)\end{array}$ & $\begin{array}{l}4.86 \\
(0.49)\end{array}$ & $\begin{array}{l}5.50 \\
(3.34)\end{array}$ & $\begin{array}{l}5.56 \\
(0.40)\end{array}$ & $\begin{array}{l}6.86 \\
(4.84)\end{array}$ & $\begin{array}{l}6.00 \\
(4.35)\end{array}$ & $\begin{array}{l}5.91 \\
(0.56)\end{array}$ & $\begin{array}{l}6.67 \\
(4.31)\end{array}$ & $\begin{array}{l}6.58 \\
(0.46)\end{array}$ & 1.99 & .165 & .041 & 2.80 & .101 & .057 \\
\hline Stress & $\begin{array}{l}13.07 \\
(7.80)\end{array}$ & $\begin{array}{l}9.93 \\
(6.70)\end{array}$ & $\begin{array}{l}9.85 \\
(1.00)\end{array}$ & $\begin{array}{l}10.86 \\
(6.15)\end{array}$ & $\begin{array}{l}10.78 \\
(0.90)\end{array}$ & $\begin{array}{l}12.76 \\
(8.21)\end{array}$ & $\begin{array}{l}12.48 \\
(7.59)\end{array}$ & $\begin{array}{l}12.58 \\
(1.15)\end{array}$ & $\begin{array}{l}13.24 \\
(7.20)\end{array}$ & $\begin{array}{l}13.34 \\
(1.04)\end{array}$ & 3.22 & .079 & .065 & 3.48 & .069 & .070 \\
\hline
\end{tabular}

Note. For all analysis, $N=49, \mathrm{n}($ Experimental $)=28, \mathrm{n}($ Waitlist control $)=21, d f=1 . A M$ and $S E$ indicate adjusted mean and standard error, respectively 
last at least one month. Figure 1 depicts the participants' progress throughout the research.

\section{Discussion}

The current study investigated the effectiveness of a brief online mindfulness-based intervention among social workers working during the Covid-19 pandemic. The study adds to the literature by determining that even a short mindfulness training program (four weekly 70-min mindfulness training sessions plus 10 to 20 min of daily meditation as homework), without an invitation to long hours of meditation, can improve psychological flexibility and self-compassion and decrease depression among social workers working during the Covid-19 pandemic. Moreover, it was found that these effects can last at least one month after the
Fig. 1 The progress of two groups over time

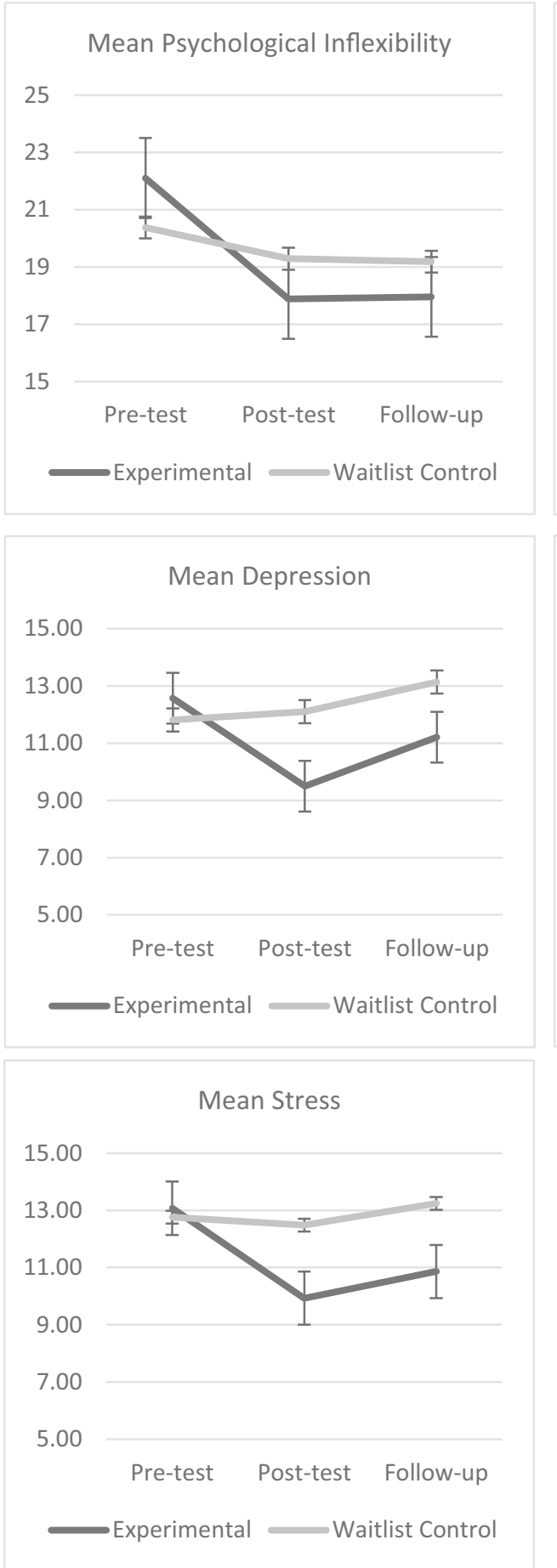

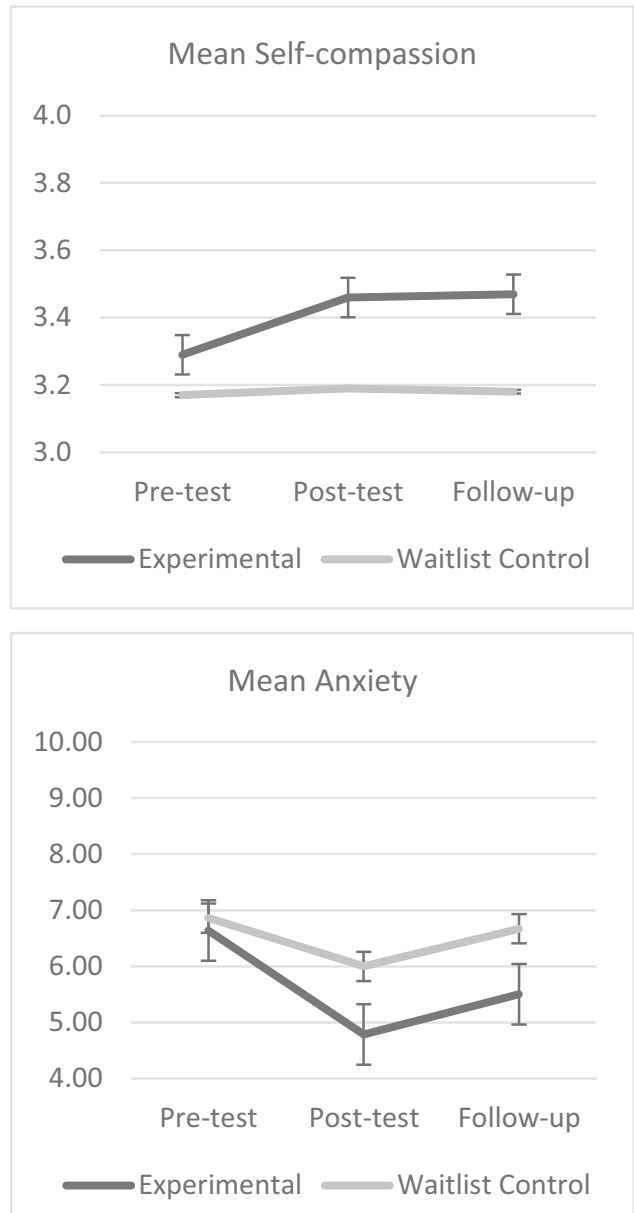


last session of the intervention. Little research has been done on the effects of short mindfulness interventions on social workers' mental health. To our knowledge, this is the first study to investigate the impact of a brief online mindfulness program on social workers amid a global health crisis.

Findings in this study that the brief mindfulness intervention improved psychological flexibility and self-compassion are broadly consistent with the result of earlier studies (e.g. Marais et al. 2020; Wasson et al. 2020; Weis et al. 2021). In the study by Marais et al. (2020), the authors reported that a standard eightweek mindfulness-based intervention improved psychological flexibility among the participants. In a study on a brief version of mindfulness intervention implementing during the Covid-19 pandemic, Weis et al. (2021) found their participants (college students) reported better self-compassion and mental health after the program. The results of the study done by Weis et al. (2021) and the present study provide the support that even a brief (fourweek) online mindfulness-based program can also promote psychological flexibility and self-compassion.

Regarding the effects of mindfulness interventions on psychological flexibility and self-compassion, the current study's findings, as well as the results of previous research (Marais et al. 2020; Wasson et al. 2020; Weis et al. 2021), are important given that promoting such skills is crucial for psychological health and well-being (Marshall and Brockman 2016). It becomes even more critical considering the harsh condition of working in a crisis such as the Covid-19 pandemic. During such severe emergencies, workers need to be more compassionate towards themselves and obtain better psychological flexibility so that they can remain mentally healthy. The current study demonstrated that brief online mindfulness interventions could improve workers' psychological flexibility and self-compassion, leading to improved mental health during the Covid-19 pandemic.

Findings in this study regarding depression are consistent with the result of one meta-analysis by Spijkerman et al. (2016), which reported that online interventions can reduce depression, anxiety, and stress. Moreover, Zhang et al. (2021) and Weis et al. (2021) reported that their brief mindfulness intervention could decrease depression, stress, and anxiety symptoms during the Covid-19 pandemic. In the current study, the brief online intervention could reduce depression; however, the modifications in anxiety and stress were not significant. It may be due to the sample of the current study that consisted of social workers working during a pandemic. During such crises, social workers, who were already under considerable work stress (Coyle et al. 2005; Kagan and Itzick 2019; Grise-Owens 2016), may carry an additional burden, causing them even more stress and anxiety. Nevertheless, the present study showed that a brief online mindfulnessbased intervention could reduce levels of depression among social workers who were under considerable pressure from dealing with a global health crisis.

\section{Limitations and Future Research Directions}

When evaluating the results, the study's limitations need to be noted. First, the study used convenience sampling with social workers, which led to a concern about external generalizability. Future studies should investigate the effectiveness of such interventions using larger and more diverse samples. Second, only self-reported questionnaires were utilized, which are susceptible to response bias. As a result, future research should include additional measurement methods such as physiological measurements. Third, the study employed quantitative methods, which have both advantages and drawbacks (Neuman 2020). Future research should use mixed methodologies to study the impact of mindfulness interventions on social workers in greater depth.

Finally, in the current study, the mechanisms of change were not examined. Further studies should investigate such mechanisms to gain a better understanding of how the intervention works. For instance, in this study, modifications in social workers' depression could be mediated by changes in self-compassion and/or psychological flexibility, as proposed by $\mathrm{Gu}$ et al. (2018) and Fledderus et al. (2013).

\section{Conclusion}

In summary, the results of the current study suggested that a four-week mindfulness intervention could be effective in improving mental health indicators of social workers who are working during a global crisis such as the Covid-19 pandemic. That is important because such interventions can be efficient ways of protecting social workers' mental health, not only in the Covid-19 pandemic but also in other emergencies such as earthquakes or wars, adding support to continuing development of brief mindfulness-based interventions. However, replication in future studies is necessary to confirm these conclusions, especially with broader samples.

Supplementary Information The online version contains supplementary material available at https://doi.org/10.1007/s12144-021-02150-3.

Data Availability The datasets generated during and/or analyzed during the current study are available from the corresponding author on reasonable request.

\section{Declarations}

Ethical Approval All procedures performed in this study were reviewed and approved by the ethical board of Hacettepe University and are following the ethical standards of the Helsinki Declaration and its later amendments. 
Informed Consent Informed consent was obtained from all participants included in the study.

Conflict of Interest The author is the developer and designer of the brief mindfulness program.

\section{References}

Acker, G. M. (2018). Self-care practices among social workers: Do they predict job satisfaction and turnover intention? Social Work in Mental Health, 16(6), 713-727. https://doi.org/10.1080/15332985. 2018.1494082.

Amerio, A., Bianchi, D., Santi, F., Costantini, L., Odone, A., Signorelli, C., et al. (2020). Covid-19 pandemic impact on mental health: A web-based cross-sectional survey on a sample of Italian general practitioners. Acta Biomed, 91(2), 83-88. https://doi.org/10.23750/ abm.v91i2.9619.

Bond, F. W., Hayes, S. C., Baer, R. A., Carpenter, K. M., Guenole, N., Orcutt, H. K., Waltz, T., \& Zettle, R. D. (2011). Preliminary psychometric properties of the acceptance and action questionnaire-II: A revised measure of psychological inflexibility and experiential avoidance. Behavior Therapy, 42(4), 676-688. https://doi.org/10. 1016/j.beth.2011.03.007.

Brown, N. (2020). Social service workers mitigating the impact of COVID-19. The global social service workforce Alliance. Retrieved 04/01/2021 from http://socialserviceworkforce.org/ resources/blog/social-service-workers-mitigating-impact-covid-19

Chakraborty, I., \& Maity, P. (2020). COVID-19 outbreak: Migration, effects on society, global environment and prevention. Science of the Total Environment, 728, 138882. https://doi.org/10.1016/j. scitotenv.2020.138882.

Chriscaden, K. (2020). Impact of COVID-19 on people's livelihoods, their health and our food systems. World Health Organization. Retrieved 19.04.2021 from https://www.who.int/news/item/13-102020-impact-of-covid-19-on-people's-livelihoods-their-health-andour-food-systems\#: :text=The $\% 20$ economic $\% 20$ and $\% 20$ social $\%$ 20disruption,the $\% 20$ end $\% 20$ of $\% 20$ the $\% 20$ year

Coyle, D., Edwards, D., Hannigan, B., Fothergill, A., \& Burnard, P. (2005). A systematic review of stress among mental health social workers. International Social Work, 48(2), 201-211. https://doi.org/ 10.1177/0020872805050492.

Craigie, M., Slatyer, S., Hegney, D., Osseiran-Moisson, R., Gentry, E., Davis, S., Dolan, T., \& Rees, C. (2016). A pilot evaluation of a mindful self-care and resiliency (MSCR) intervention for nurses. Mindfulness, 7(3), 764-774. https://doi.org/10.1007/s12671-0160516-X.

Cuartero, M. E., \& Campos-Vidal, J. F. (2019). Self-care behaviours and their relationship with satisfaction and compassion fatigue levels among social workers. Social Work in Health Care, 58(3), 274 290. https://doi.org/10.1080/00981389.2018.1558164.

Dawson, A. F., Brown, W. W., Anderson, J., Datta, B., Donald, J. N., Hong, K., Allan, S., Mole, T. B., Jones, P. B., \& Galante, J. (2020). Mindfulness-based interventions for university students: A systematic review and meta-analysis of randomised controlled trials. Applied Psychology: Health and Well-Being, 12(2), 384-410. https://doi.org/10.1111/aphw.12188.

Demarzo, M., Montero-Marin, J., Puebla-Guedea, M., Navarro-Gil, M., Herrera-Mercadal, P., Moreno-González, S., Calvo-Carrión, S., Bafaluy-Franch, L., \& Garcia-Campayo, J. (2017). Efficacy of 8and 4-session mindfulness-based interventions in a non-clinical population: A controlled study [original research]. Frontiers in Psychology, 8(1343). https://doi.org/10.3389/fpsyg.2017.01343
Deniz, M. E., Kesici, Ș., \& Sümer, A. S. (2008). THE VALIDITY AND RELIABILITY OF THE TURKISH VERSION OF THE SELFCOMPASSION SCALE. Social Behavior and Personality: An International Journal, 36(9), 1151-1160. https://doi.org/10.2224/ sbp.2008.36.9.1151.

Farris, S. R., Grazzi, L., Holley, M., Dorsett, A., Xing, K., Pierce, C. R., Estave, P. M., O’Connell, N., \& Wells, R. E. (2021). Online mindfulness may target psychological distress and mental health during COVID-19. Global Advances in Health and Medicine, 10, 21649561211002461 . https://doi.org/10.1177/ 21649561211002461.

Fledderus, M., Bohlmeijer, E. T., Fox, J.-P., Schreurs, K. M. G., \& Spinhoven, P. (2013). The role of psychological flexibility in a self-help acceptance and commitment therapy intervention for psychological distress in a randomized controlled trial. Behaviour Research and Therapy, 51(3), 142-151. https://doi.org/10.1016/j. brat.2012.11.007.

Gockel, A., \& Deng, X. (2016). Mindfulness training as social work pedagogy: Exploring benefits, challenges, and issues for consideration in integrating mindfulness into social work education. Journal of Religion \& Spirituality in Social Work: Social Thought, 35(3), 222-244. https://doi.org/10.1080/15426432.2016.1187106.

Griffiths, A., Royse, D., Murphy, A., \& Starks, S. (2019). Self-care practice in social work education: A systematic review of interventions. Journal of Social Work Education, 55(1), 102-114. https://doi.org/ 10.1080/10437797.2018.1491358.

Grise-Owens, E. (2016). The A-to-Z self-care handbook for social workers and other helping professionals. New Social Worker Press

Gu, J., Cavanagh, K., \& Strauss, C. (2018). Investigating the specific effects of an online mindfulness-based self-help intervention on stress and underlying mechanisms. Mindfulness, 9(4), 1245-1257. https://doi.org/10.1007/s12671-017-0867-y.

Haleem, A., Javaid, M., \& Vaishya, R. (2020). Effects of COVID-19 pandemic in daily life. Current medicine research and practice, 10(2), 78-79. https://doi.org/10.1016/j.cmrp.2020.03.011.

Hayes, S. C., Luoma, J. B., Bond, F. W., Masuda, A., \& Lillis, J. (2006). Acceptance and commitment therapy: Model, processes and outcomes. Behaviour Research and Therapy, 44(1), 1-25. https://doi. org/10.1016/j.brat.2005.06.006.

Hick, S. F. (2008). A personal journey to mindfulness: Implications for social work practice. Reflections: Narratives of Professional Helping, 14(2), 16-23.

Howarth, A., Smith, J. G., Perkins-Porras, L., \& Ussher, M. (2019). Effects of brief mindfulness-based interventions on health-related outcomes: A systematic review. Mindfulness, 10(10), 1957-1968. https://doi.org/10.1007/s12671-019-01163-1.

Hughes, M., Brown, S. L., Campbell, S., Dandy, S., \& Cherry, M. G. (2021). Self-compassion and anxiety and depression in chronic physical illness populations: A systematic review. Mindfulness., 12, 1597-1610. https://doi.org/10.1007/s12671-021-01602-y.

Inwood, E., \& Ferrari, M. (2018). Mechanisms of change in the relationship between self-compassion, emotion regulation, and mental health: A systematic review. Applied Psychology: Health and Well-Being, 10(2), 215-235. https://doi.org/10.1111/aphw.12127.

Jatta, J. W., Sanyang, Y., Nebongo, D., Touray, T. A., Sanyang, D., \& Senghore, T. (2021). Preparedness of healthcare workers towards handling COVID-19 outbreak in the Gambia. SciMedicine Journal, 3, 36-42. https://doi.org/10.28991/SciMedJ-2021-03-SI-5.

Kabat-Zinn, J. (2003). Mindfulness-based interventions in context: Past, present, and future. Clinical Psychology: Science and Practice, 10(2), 144-156. https://doi.org/10.1093/clipsy.bpg016.

Kagan, M., \& Itzick, M. (2019). Work-related factors associated with psychological distress among social workers. European Journal of Social Work, 22(1), 30-42. https://doi.org/10.1080/13691457.2017. 1357021. 
Lewis, M. L., \& King, D. M. (2019). Teaching self-care: The utilization of self-care in social work practicum to prevent compassion fatigue, burnout, and vicarious trauma. Journal of Human Behavior in the Social Environment, 29(1), 96-106. https://doi.org/10.1080/ 10911359.2018.1482482.

Lim, J., Leow, Z., Ong, J., Pang, L.-S., \& Lim, E. (2021). Effects of webbased group mindfulness training on stress and sleep quality in Singapore during the COVID-19 pandemic: Retrospective equivalence analysis. JMIR Mental Health, 8(3), e21757. https://doi.org/ $10.2196 / 21757$

Lovibond, P. F., \& Lovibond, S. H. (1995). The structure of negative emotional states: Comparison of the depression anxiety stress scales (DASS) with the Beck depression and anxiety inventories. Behaviour Research and Therapy, 33(3), 335-343. https://doi.org/ 10.1016/0005-7967(94)00075-U.

Marais, G. A. B., Lantheaume, S., Fiault, R., \& Shankland, R. (2020). Mindfulness-based programs improve psychological flexibility, mental health, well-being, and time Management in Academics. European Journal of Investigation in Health, Psychology and Education, 10(4), 1035-1050 https://www.mdpi.com/2254-9625/ $10 / 4 / 73$

Marshall, E. J., \& Brockman, R. N. (2016). The relationships between psychological flexibility, self-compassion, and emotional well-being. Journal of Cognitive Psychotherapy, 30(1), 60-72. https://doi. org/10.1891/0889-8391.30.1.60.

Matiz, A., Fabbro, F., Paschetto, A., Cantone, D., Paolone, A. R., \& Crescentini, C. (2020). Positive impact of mindfulness meditation on mental health of female teachers during the COVID-19 outbreak in Italy. International Journal of Environmental Research and Public Health, 17(18), 6450 https://www.mdpi.com/1660-4601/ $17 / 18 / 6450$

McCusker, P. (2021). Critical mindfulness in social Work: Exploring the Potential of Reflexive Self-Care in the Journey from Student to Social Worker. The British Journal of Social Work. https://doi.org/ 10.1093/bjsw/bcaa246

McGarrigle, T., \& Walsh, C. A. (2011). Mindfulness, self-care, and wellness in social work: Effects of contemplative training. Journal of Religion \& Spirituality in Social Work: Social Thought, 30(3), 212 233. https://doi.org/10.1080/15426432.2011.587384.

NASW. (2020a). Coronavirus (COVID-19). National Association of Social Workers. Retrieved 19/04/2021 from https://www. socialworkers.org/Practice/Infectious-Diseases/Coronavirus

NASW. (2020b). Self-Care for Social Workers. National Association of Social Workers. Retrieved 19/04/2021 from https://www. socialworkers.org/Practice/Infectious-Diseases/Coronavirus/SelfCare-During-the-Coronavirus-Pandemic

Neff, K. D. (2003a). The development and validation of a scale to measure self-compassion. Self and Identity, 2(3), 223-250. https://doi. org/10.1080/15298860309027.

Neff, K. D. (2003b). Self-compassion: An alternative conceptualization of a healthy attitude toward oneself. Self and Identity, 2(2), 85-101. https://doi.org/10.1080/15298860309032.

Neff, K. D. (2016). The self-compassion scale is a valid and theoretically coherent measure of self-compassion. Mindfulness, 7(1), 264-274. https://doi.org/10.1007/s12671-015-0479-3.

Neuman, W. L. (2020). Social research methods: Qualitative and quantitative approaches (Eighth ed.). Inc: Pearson Education.

Sariçam, H. (2018). The psychometric properties of Turkish version of depression anxiety stress Scale-21 (DASS-21) in health control and clinical samples. Journal of Cognitive Behavioral Psychotherapy and Research, 7(1), 19-30.
Segal, Z. V., Williams, J. M. G., \& Teasdale, J. D. (2013). Mindfulnessbased cognitive therapy for depression (2nd ed.). Guilford Press

Spijkerman, M. P. J., Pots, W. T. M., \& Bohlmeijer, E. T. (2016). Effectiveness of online mindfulness-based interventions in improving mental health: A review and meta-analysis of randomised controlled trials. Clinical Psychology Review, 45, 102-114. https://doi. org/10.1016/j.cpr.2016.03.009.

Stanley, N., Manthorpe, J., \& White, M. (2006). Depression in the profession: Social workers' experiences and perceptions. The British Journal of Social Work, 37(2), 281-298. https://doi.org/10.1093/ bjsw/bc1058.

Storey, J., \& Billingham, J. (2001). Occupational stress and social work. Social Work Education, 20(6), 659-670. https://doi.org/10.1080/ 02615470120089843a.

Vindegaard, N., \& Benros, M. E. (2020). COVID-19 pandemic and mental health consequences: Systematic review of the current evidence. Brain, Behavior, and Immunity, 89, 531-542. https://doi.org/10. 1016/j.bbi.2020.05.048.

Vonderlin, R., Biermann, M., Bohus, M., \& Lyssenko, L. (2020). Mindfulness-based programs in the workplace: A meta-analysis of randomized controlled trials. Mindfulness, 11(7), 1579-1598. https://doi.org/10.1007/s12671-020-01328-3.

Wasson, R. S., Barratt, C., \& O'Brien, W. H. (2020). Effects of mindfulness-based interventions on self-compassion in health care professionals: A meta-analysis. Mindfulness, 11(8), 1914-1934. https://doi.org/10.1007/s12671-020-01342-5.

Weis, R., Ray, S. D., \& Cohen, T. A. (2021). Mindfulness as a way to cope with COVID-19-related stress and anxiety. Counselling and Psychotherapy Research, 21(1), 8-18. https://doi.org/10.1002/capr. 12375.

Willis, N. G., \& Molina, V. (2018). Self-care and the social worker: Taking our place in the code. Social Work, 64(1), 83-86. https:// doi.org/10.1093/sw/swy049.

Yavuz, F., Ulusoy, S., Iskin, M., Esen, F. B., Burhan, H. S., Karadere, M. E., \& Yavuz, N. (2016). Turkish version of acceptance and action questionnaire-II (AAQ-II): A reliability and validity analysis in clinical and non-clinical samples. Klinik Psikofarmakoloji BülteniBulletin of Clinical Psychopharmacology, 26(4), 397-408. https:// doi.org/10.5455/bcp.20160223124107.

Zamorano, A. C., Marchena-Consejero, E., Hervías-Ortega, F., Menacho-Jiménez, I., \& Mera-Cantillo, C. (2017). A review of online psychological interventions proceedings of the 5th international conference on technological ecosystems for enhancing Multiculturality. Cádiz, Spain. https://doi.org/10.1145/3144826. 3145410

Zhang, H., Zhang, A., Liu, C., Xiao, J., \& Wang, K. (2021). A brief online mindfulness-based group intervention for psychological distress among Chinese residents during COVID-19: A pilot randomized controlled trial. Mindfulness., 12, 1502-1512. https://doi.org/ 10.1007/s12671-021-01618-4.

Zhou, X., Guo, J., Lu, G., Chen, C., Xie, Z., Liu, J., \& Zhang, C. (2020). Effects of mindfulness-based stress reduction on anxiety symptoms in young people: A systematic review and meta-analysis. Psychiatry Research, 289, 113002. https://doi.org/10.1016/j.psychres.2020. 113002.

Publisher's Note Springer Nature remains neutral with regard to jurisdictional claims in published maps and institutional affiliations. 